\title{
A Scheme for Analysis and Design of Analogue Circuits
}

\author{
R. Rohith Krishnan ${ }^{1 *}$ and S. Krishnakumar ${ }^{2}$
}

Department of Electronics, School of Technology and Applied Sciences, M. G. University Regional Centre, Edappally, Ernakulam - 682024, Kerala, India; rohithpunnoor@gmail.com, drkrishsan@gmail.com

\begin{abstract}
Network theorems or circuit theorems are special aids, which can reduce the amount of effort involved in circuit analysis to a considerable degree. For linear networks, there exists interdependence between various network theorems. Thus, by careful analysis, one theorem can verify in terms of another theorem and it is advantageous for pedagogical reasons. A scheme for analogue circuit analysis is presented in this paper. Here piece-by-piece or part-by-part analyzing strategy is employed which can reduce the complexity associated with analyzing or biasing design of large analogue circuits. Fixatornorator pair plays the key role in this methodology. Hybrid equivalent circuit, an alternative for Thevenin's or Norton's equivalent model is realized with fixator-norator pair, and is seen to be more dynamic and flexible since it contains both voltage source and current source. Thevenin's theorem, compensation theorem and maximum power transfer theorem are analyzed in terms of fixator norator pairs, and the study indicates the importance and capabilities of fixator-norator pair and hence hybrid equivalent circuit in analogue circuit design and analysis.
\end{abstract}

Keywords: Compensation Theorem, Fixator-norator Pair, Hybrid Equivalent Circuit, Maximum Power Transfer Theorem, Thevenin's Theorem

\section{Introduction}

Analogue circuit design is an artwork where the skilled designers finds the interactions and inter relations between various design parameters. The design of analogue circuit is a two-step process. The AC performance design and the DC biasing design. In AC design, active devices are replaced with their linear equivalent models and here the circuit is treated entirely linear. The DC biasing design, where most of the difficulty in analogue design resides, is to get operating points fixed at the targeted critical values. As the circuit grows, the difficulty increases and in turn results in multiple or unstable operating points. The reason for this difficulty is that a traditional method treats the circuit as a whole with no separation between linear and nonlinear components. Moreover, DC sources are prefixed at certain locations of circuit and it results in reduced flexibility. Here we need to take a number of iterations to fix the operating points.

Network theorems or circuit theorems can simplify the effort in circuit analysis to a considerable degree.
They are helpful to reduce a larger network containing a number of independent sources, linear dependent sources, linear resistors, capacitors and inductors to a smaller network and thus the steps involved in a targeted analysis gets reduced. Sometimes, verification of one theorem based on another theorem is advantageous 1,2 and it may give a shortcut to the required answer. Moreover, such verification results in better understanding about the so-called theorems and avoids wrong usage of equivalent models.

Thevenin's and Norton's equivalent models are the two popular linear circuit models that replace a linear circuit containing a number of sources and impedances into a source and single equivalent impedance. They are helpful for many circuit analysis operations like source transformation, DC analysis, frequency analysis etc. One of the less notified drawbacks of these models is that they depend only on source section and gives less care to load end. This sometimes limits their applications, which may be discussed in following sections.

\footnotetext{
*Author for correspondence
} 
Fixators and norators $4^{4-7}$ are the emerging tools in circuit analysis. They are always used in pairs. Fixators are two terminal devices with both the voltage across and current through the component are fixed. For norators, voltage across and current through them can take any value. There is a third component nullator, which has the voltage across and current through them equals zero, Nullor is the combination of norator and nullator. Ideal operational amplifiers are the examples of nullors and therefore in practical cases, operational amplifiers are used to model fixator-norator pairs cannot directly model fixator-norator pairs, so ideal controlled sources with very high gain can be used to mimic the pair.

Section 2 introduces verification of Thevenin's theorem in terms of fixator norator pair. Sections 3 and 4 describe about verification of Compensation and Maximum power transfer theorem. Section 5 discuss about construction of equivalent models. Finally, Section 6 concludes the discussion.

\section{Analysis of Thevenin's Theorem}

Figure $1(\mathrm{a})$ is a network consisting of ' $\mathrm{n}$ ' number of independent voltage sources and ' $m$ ' number of independent current sources and Figure 1 (b) is its Thevenin's equivalent circuit. The voltage across load is marked as $\mathrm{V}_{\text {load }}$ and load current is $\mathrm{I}_{\text {load }}$. At the next step, we remove the load $R_{\perp}$ and instead place fixator-norator pair. As discussed in ${ }^{4-6}$ replacement of $\mathrm{R}_{\mathrm{L}}$ with proper fixator-norator pair makes no change to the working conditions of network to the left of $\mathrm{R}_{\mathrm{L}}$. Figure 2 shows the circuit arrangement. The current through voltage source $\mathrm{V}_{\text {load }}$ controls the norator. In this arrangement, we actually draw current $\mathrm{I}_{\text {load }}$ from the source network, so port $\mathrm{L}_{1}$ is at a potential $\mathrm{V}_{\text {load }}$ as indicated in Figure 1. If we connect ports $\mathrm{L}_{1}$ and $\mathrm{L}_{2}$, it will be the equivalent circuit for network in Figure 1 in terms of fixator-norator pair. A voltage $V_{\text {load }}$ is dropped across the norator and the norator current is $I_{\text {load }}$. Therefore, in this case norator is the equivalent for $\mathrm{R}_{\mathrm{L}}$. Addition of fixator-norator pair makes no change to the actual circuit. The added fixator does not consume or provide any power. Next, we remove all the sources by replacing them with their internal resistance, i.e., voltage sources are replaced with short circuit and current source are replaced with open circuit. The modified circuit is shown in Figure 3. Since we replaced the sources with their internal resistances, at this point when we look into the network from its output port, there we see Thevenin's equivalent resistance, $\mathrm{R}_{\mathrm{Th}}$.

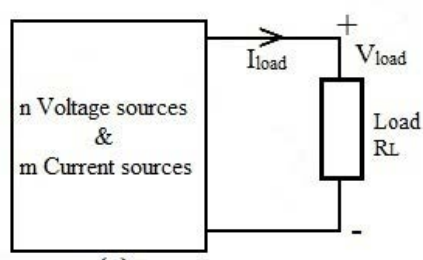

(a)

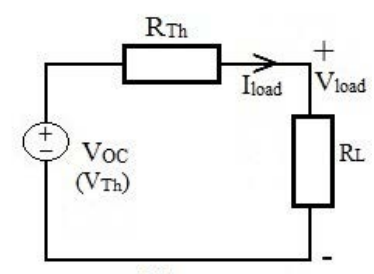

(b)
Figure 1. (a) network with 'n' number of voltage sources and ' $m$ ' number of current sources. (b) its equivalent Thevenin's model.

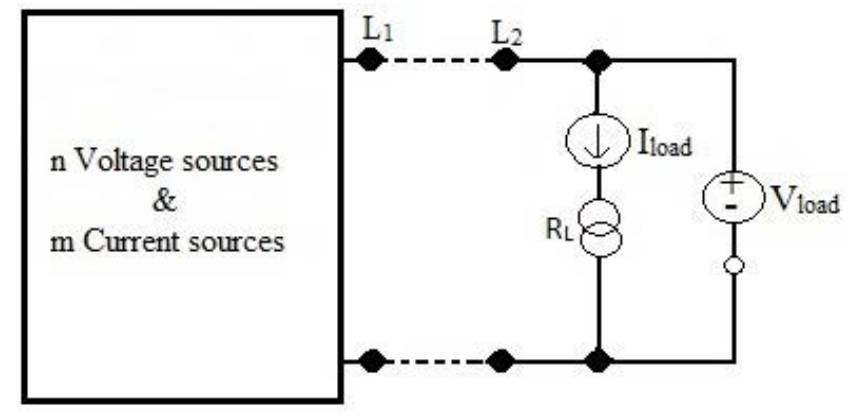

Figure 2. Applying fixator norator pair to output port.

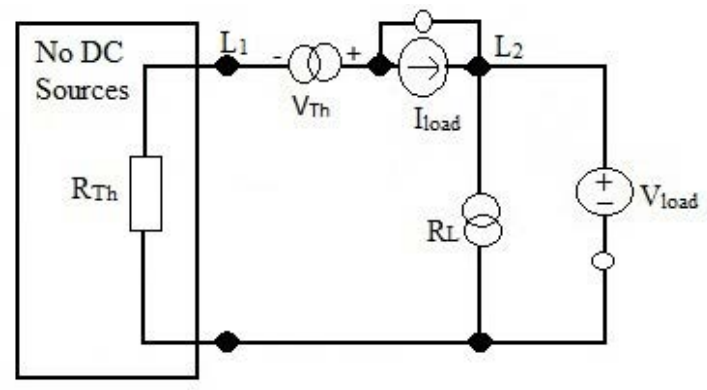

Figure 3. All the sources of circuit in Figure 1(a)are replaced with their internal resistances.

The voltage fixator $\operatorname{Fx}\left(\mathrm{V}_{\text {load }}, 0\right)$ fixes node $\mathrm{L}_{2}$ at a voltage $\mathrm{V}_{\text {load }}$ at the same time, current fixator $\operatorname{Fx}\left(0, \mathrm{I}_{\text {load }}\right)$ keeps the current through $\mathrm{R}_{\mathrm{L}}$ fixed at $\mathrm{I}_{\text {load }}$. Moreover, the norator associated with the current fixator gives the value of $\mathrm{T}_{\mathrm{Th}}$. This is what the Thevenin's theorem states. Here we have a single equivalent source $V_{T h}$, equivalent resistance 
$\mathrm{R}_{\mathrm{Th}}$, and load. Keep in mind that neither $\mathrm{V}_{\mathrm{Th}}$ nor $\mathrm{R}_{\mathrm{Th}}$ are controlled by load. Load can affect only output port values that are $\mathrm{V}_{\text {load }}$ and $\mathrm{I}_{\text {load }}$. There are situations where we want to interchange some of the components from both sides of the ports. In such cases to meet the requirements of networks like one we discuss, we need a dynamic model like $\mathrm{H}$-model. Let us see what change is made by an $\mathrm{H}$-model when it is used in place of Thevenin's equivalent model. It is shown in Figure 4.

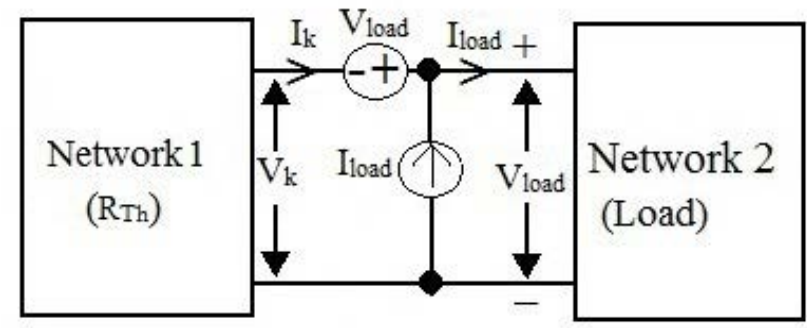

Figure 4. H-model representation of Figure 1(a).

By analyzing Figure 1 and Figure 4, we get,

$V_{\text {load }}=V_{H}=V_{T h}-I_{\text {load }} R_{T h}$

And

$I_{\text {load }}=I_{H}=I_{s c}-\frac{V_{\text {load }}}{R_{T h}}$

The null port $\mathrm{K}$ indicates that $\mathrm{N}_{1}$ consume no power, hence total power consumption is reduced.

\section{Analysis of Compensation Theorem}

Compensation theorem can take two forms, the first and simplest form states, in a linear network, any element can be replaced by an independent voltage source, whose value is equal to voltage drop across the element. In the second form, as the resistance $\mathrm{R}$ of a branch carrying a current $\mathrm{I}$ is incremented to $\mathrm{R}+\Delta \mathrm{R}$, then the compensation voltage to minimize the change $V_{C}$ is given by $I \Delta R$. Consider a simple circuit as shown in Figure 5. Load voltage is found to be $2.874 \mathrm{~V}$ and load current is $2.874 \mathrm{~mA}$. Let the value of load resistor changes from $1 \mathrm{~K} \Omega$ to $1.1 \mathrm{~K} \Omega$. If we want to kept voltage across load unchanged $(2.874 \mathrm{~V}$ in this case), we have to redesign value of the source or resistors. Now we are going to redesign value of $R_{2}$ using fixator $\operatorname{Fx}(2.874 \mathrm{~V}, 0)$. Circuit arrangement is shown in Figure 6.
The pairing norator shows a drop of $3.135 \mathrm{~V}$ and a current of $6.711 \mathrm{~mA}$ flows through it. Thus, replacement of $\mathrm{R}_{2}$ by a voltage source of $3.135 \mathrm{~V}$ can solve the issue. Updating the value of $R_{2}$ as $467.1 \Omega$ or replacing $R_{2}$ by a current source of $6.711 \mathrm{~mA}$ are other possible substitutions.

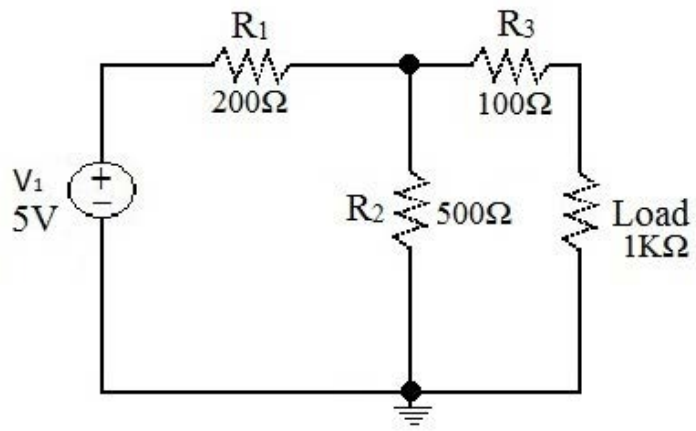

Figure 5. A simple resistor network.

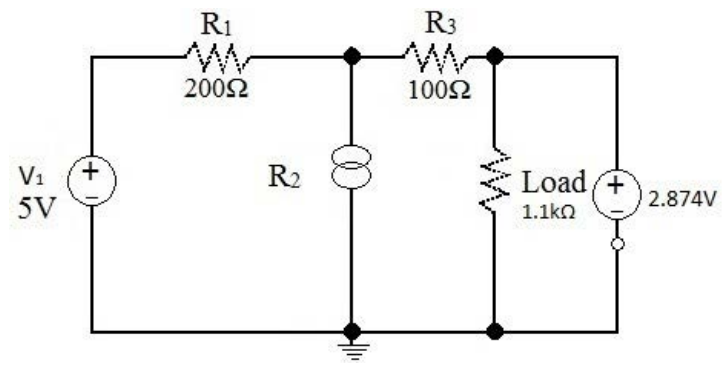

Figure 6. Redesign of resistor $\mathrm{R}_{2}$.

Now consider the second form of compensation theorem. Here we have to find the compensation voltage $\mathrm{V}_{\mathrm{C}}$, which compensate the change in load. Fixator can easily find the value of $\mathrm{V}_{\mathrm{C}}$ in a similar way as done in Figure 6. But how can we do with less power consumption? $\mathrm{H}$-modeling can be done with the help of fixators. The circuit arrangement is shown in Figure 7. Simulation indicates that value of $\mathrm{V}_{\mathrm{C}}=287.4 \mathrm{mV}$.

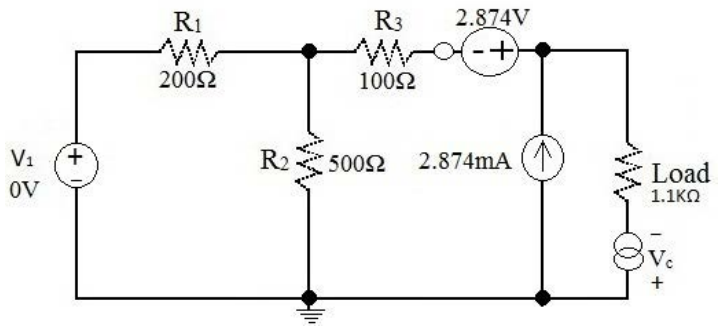

Figure 7. Finding compensation voltage $\mathrm{V}_{\mathrm{C}}$. 


\section{Analysis of Maximum Power Transfer Theorem}

In many instance we need to adjust load impedance for maximum power transfer from source to load. Maximum power transfer theorem defines the relationship between load impedance and internal impedance of source for maximum power transfer. We can verify the Maximum power transfer theorem by taking a sample network and analysing it. It is important to keep in mind that this theorem is defined for networks with sources having fixed source impedance. Figure 8(a) shows a sample network and Figure $8(\mathrm{~b})$ is its Thevenin's equivalent circuit.

According to Maximum power transfer theorem, maximum power transfer or $50 \%$ efficiency results if the internal resistance of source (or $\mathrm{R}_{\mathrm{Th}}$ in this case) is equal to the load resistance. We try to prove that if efficiency is $50 \%$, then load resistance equals to $\mathrm{R}_{\mathrm{Th}}$.

From Figure $8(\mathrm{a})$, we have $\mathrm{V}_{\mathrm{OC}}$ at load end $=10.91 \mathrm{~V}$, which is the $\mathrm{V}_{\mathrm{Th}}$. For $50 \%$ efficiency,

$\mathrm{V}_{\mathrm{L}}=\frac{\mathrm{V}_{\mathrm{OC}}}{2}$

Or,

$I_{L}=\frac{I_{S C}}{2}$

Take the first condition and proceed, remove load from the circuit as shown in Figure 8(a) and instead place a voltage fixator to fix load voltage at $\mathrm{V}_{\mathrm{OC}} / 2$. It is shown in Figure 9. Here current through the norator is controlled by the current through fixator.

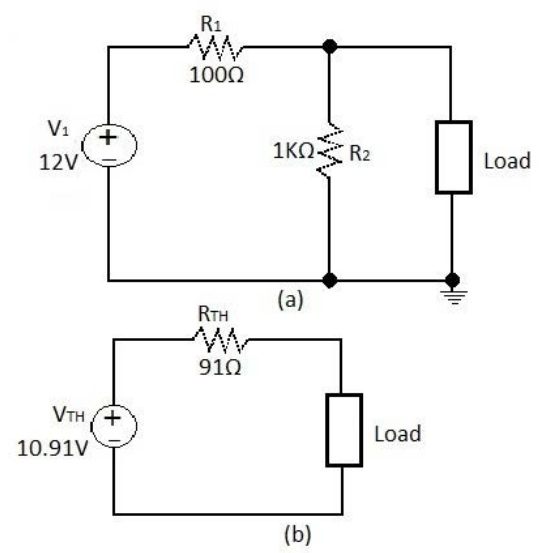

Figure 8. (a) A sample network. (b) its Thevenin equivalent.

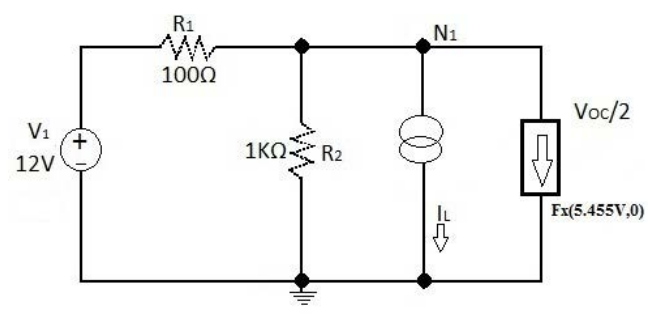

Figure 9. Load is replaced by fixator-norator pair at $50 \%$ efficiency condition.

After simulation, the norator current $\mathrm{I}_{\text {load }}$ is observed as $60 \mathrm{~mA}$, which results in a load resistance of $91 \Omega$. From the analysis of compensation theorem, we have,

$\mathbf{R}_{\mathrm{Th}}=\frac{\mathrm{V}_{\text {load }}}{\mathrm{I}_{\mathrm{SC}}-\mathrm{I}_{\text {load }}}$

Here, $\mathrm{V}_{\text {load }}=5.455 \mathrm{~V}, \mathrm{I}_{\mathrm{SC}}-\mathrm{I}_{\text {load }}=60 \mathrm{~mA}$. Therefore, $\mathrm{R}_{\mathrm{Th}}$ must be $91 \Omega$. These results indicate that, for maximum power transfer, load in Figure 8(a) must be $91 \Omega$. It is now easy to calculate $\mathrm{V}_{\mathrm{Th}}$ as $10.91 \mathrm{~V}$. This verifies maximum power transfer theorem in terms of fixator norator pair. Again, H-modeling may also be employed to find new value of load for maximum power transfer, with $\mathrm{V}_{\mathrm{H}}=$ $\mathrm{V}_{\mathrm{OC}} / 2$ and $\mathrm{I}_{\mathrm{H}}=\mathrm{I}_{\mathrm{SC}} / 2$. In addition, it is now easy to find value of load for a given efficiency provided fixators of required values.

\section{Construction of Equivalent Models}

Equivalent models are necessary for the analysis of analogue circuits. Consider a common emitter (C.E) amplifier with voltage divider biasing as shown in Figure 10. To construct its Thevenin's equivalent model, at first, we have to make its linear model. Figure 11 shows the simplified small signal equivalent circuit with virtual biasing sources.

For the base side, i.e., input port of amplifier, the biasing can be provided with Thevenin's equivalent of voltage divider network and the network reduces to a $6 \mathrm{~V}$ DC source and a series $10 \mathrm{~K} \Omega$ resistor. Now, using fixatornorator pair, we can set various amplifier parameters like $\mathrm{V}_{\mathrm{C}}, \mathrm{V}_{\mathrm{E}}$ etc. by re-designing the value of $\mathrm{V}_{\mathrm{Th}}, \mathrm{R}_{\mathrm{Th}}, \mathrm{DC}$ sources or other resistors. 


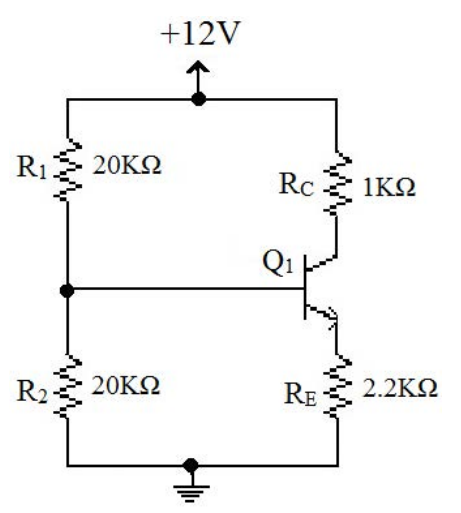

Figure 10. A Common emitter amplifier with voltage divider biasing.

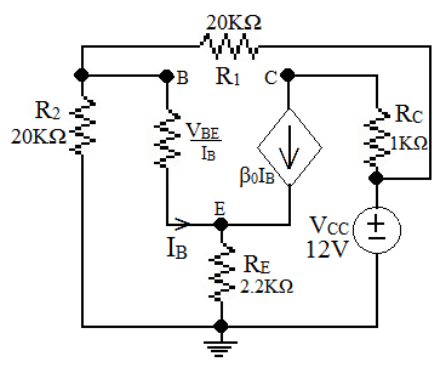

Figure 11. Small signal equivalent model of the C.E amplifier.

We can construct Thevenin's equivalent model of the above C.E amplifier looking from the load end by using fixator-norator pair. The open circuited (no load) voltage at the collector node of Figure 11 gives the value of $\mathrm{V}_{\text {fh. }}$. By applying maximum power transfer theorem, a fixator $\mathrm{Fx}\left(\mathrm{V}_{\mathrm{Th}} / 2,0\right)$ connected to collector node along with its pairing norator provides the value of $\mathrm{R}_{\mathrm{Th}}$. For a selected transistor, equivalent circuit and port characteristic curve are shown in Figure 12 (a) and Figure 12 (b).

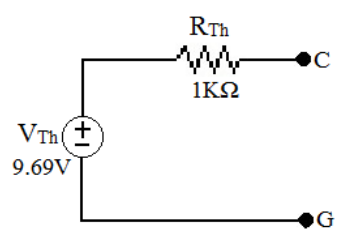

(a)

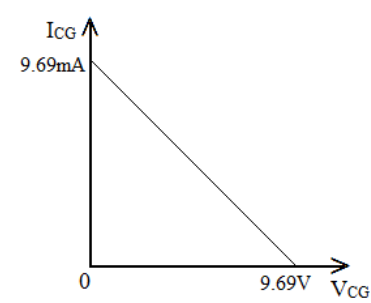

(b)
Figure 12. (a) Thevenin's equivalent circuit. (b) Port characteristic curve.

Maximum voltage drop occurs across the load when $R_{L}=R_{T h}$. I.e., maximum efficiency is $50 \%$. But for a linear network with fixed $\mathrm{R}_{\mathrm{Th}}$, how can we make the effect of zero $\mathrm{R}_{\mathrm{Th}}$ for the load without removing/altering any component in source network? If it is so happened, we get $\mathrm{V}_{\text {load }}=\mathrm{V}_{\mathrm{Th}}$ and $\mathrm{I}_{\text {load }}=\mathrm{I}_{\mathrm{SC}}\left(\right.$ where $\left.\mathrm{I}_{\mathrm{SC}}=\mathrm{V}_{\mathrm{Th}} / \mathrm{R}_{\mathrm{Th}}\right)$. A method similar to $\mathrm{H}$-modeling can be used for this purpose with $\mathrm{V}_{\mathrm{H}}=\mathrm{V}_{\mathrm{Th}} / 2$ and $\mathrm{I}_{\mathrm{H}}=\mathrm{V}_{\mathrm{H}} / \mathrm{R}_{\mathrm{Th}}$. It is shown in Figure 13.

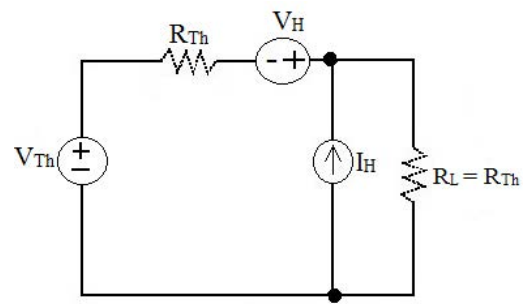

Figure 13. Making $\mathrm{R}_{\mathrm{Th}}=0$ for the load.

Similiarly, for a linear network, we can find the value of $R_{T h}$ by replacing $R_{L}$ in Figure 13 by fixator $\operatorname{Fx}\left(V_{T h}, 0\right)$ and $\mathrm{I}_{\mathrm{H}}$ by its pairing norator. $\mathrm{R}_{\mathrm{Th}}$ is $\mathrm{V}_{\mathrm{H}} / \mathrm{I}_{\mathrm{H}}$ or $\mathrm{V}_{\mathrm{Th}} /\left(2 \mathrm{I}_{\mathrm{H}}\right)$. The circuit arrangement is shown in Figure 14.

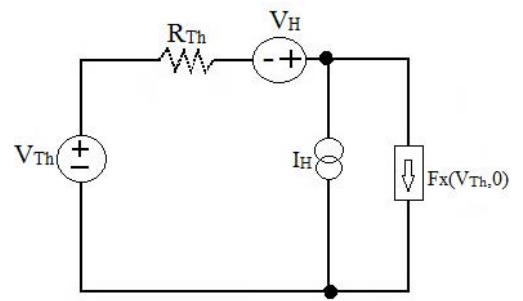

Figure 14. Finding the value of $\mathrm{R}_{\mathrm{Th}}$.

\section{Conclusion}

A scheme for analysis and biasing design of analogue circuit is presented. Thevenin's theorem has been verified using fixator-norator pair. In addition, Compensation theorem and Maximum power transfer theorem have also been analysed. Here we can see the interdependence between Thevenin's theorem and other network theorems. Hybrid equivalent circuit is presented and it is seen to be a good alternative for Thevenin's and Norton's equivalent circuits. Two forms of compensation theorem have been discussed and verified in this article. The method adopted to verify Maximum power transfer theorem is useful to design the value of $R_{L}$ as per the required efficiency. At the end, construction of equivalent models using fixators have been worked out. 


\section{References}

1. Johnson DH. Origins of the equivalent circuit concept. Johnson. 2001 Aug 11.

2. Judd FF, Chirlian PM. The Application of the compensation theorem in the proof of Thevenin's and Norton's Theorem. IEEE Transactions on Education. 1970 Aug.

3. Hashemian R. Hybrid equivalent circuit, an alternative to Thevenin and Norton equivalents, its properties and applications. Proceedings of IEEE International Midwest Symposium on Circuits and Systems, Cancun, Mexico; 2009 Aug.

4. Hashemian R. Application of Fixators-Norator pairs in designing active loads and current mirrors in analog integrated circuits. IEEE Transactions On Very Large Scale Integration (VLSI) Systems. 2012 Dec; 20(12).
5. Krishnan RR, Krishnakumar S. Practical biasing design for analog circuits. International Journal of Engineering Research and Technology. 2014 Jul; 3(7).

6. Krishnan RR, Krishnakumar S, Hashemian R. A method to modify/correct the performance of amplifiers. International Journal of Scientific and Technology Research. 2015 Jan; 4(1).

7. Hashemian R. A methodology to simulate circuits with nonlinear devices Proceedings of MWSCAS 2005, Cincinnati, Ohio; 2005 Aug 7-10.

8. Hashemian R. Local biasing and the use of nullator-norator pairs in analog circuits designs. VLSI Design. 2010; 2010:19-30.

9. Gadjeva ED, Gadzhev NG. A nullor approach to computer-aided analogue circuit diagnosis. Inverse Problems in Science and Engineering. 2012 Jan; 20(1):127-36. 